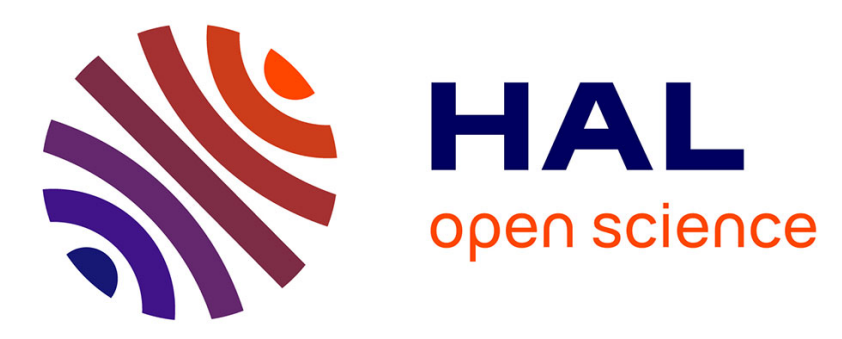

\title{
Electrical resistivity imaging for detecting soil cracking at the centimetric scale
}

\author{
Anatja Samouëlian, Isabelle I. Cousin, Guy Richard, Alain Tabbagh, Ary \\ Bruand
}

\section{- To cite this version:}

Anatja Samouëlian, Isabelle I. Cousin, Guy Richard, Alain Tabbagh, Ary Bruand. Electrical resistivity imaging for detecting soil cracking at the centimetric scale. Soil Science Society of America Journal, 2003, 67 (5), pp.1319-1326. hal-02681528

\section{HAL Id: hal-02681528 \\ https://hal.inrae.fr/hal-02681528}

Submitted on 31 May 2020

HAL is a multi-disciplinary open access archive for the deposit and dissemination of scientific research documents, whether they are published or not. The documents may come from teaching and research institutions in France or abroad, or from public or private research centers.
L'archive ouverte pluridisciplinaire HAL, est destinée au dépôt et à la diffusion de documents scientifiques de niveau recherche, publiés ou non, émanant des établissements d'enseignement et de recherche français ou étrangers, des laboratoires publics ou privés. 


\title{
SOIL SCIENCE SOCIETY OF AMERICA JOURNAL
}

\section{DIVISION S-1-SOIL PHYSICS}

\section{Electrical Resistivity Imaging for Detecting Soil Cracking at the Centimetric Scale}

\author{
Anatja Samouëlian,* Isabelle Cousin, Guy Richard, Alain Tabbagh, and Ary Bruand
}

\begin{abstract}
Electrical resistivity measurements at high resolution $(1.5-\mathrm{cm}$ electrode spacing) were performed to detect, from the soil surface, small cracks developing within the soil. We recorded a vertical electrical pseudo-section in a decimetric undisturbed homogenous soil block (silt loam) for different artificial cracking stages. Because of the unusually reduced electrode spacing associated with an air-dried soil surface, a specific $\mathrm{Cu} / \mathrm{CuSO}_{4}$ electrode was designed for precision wet contact at given points. The apparent resistivity measurements of the pseudosection and the interpreted data inverted by using the Res2Dinv software are discussed. The range of interpreted electrical resistivity associated with cracking is considerable, (from 168 to $2185 \Omega \mathrm{m}$ ) because the cracks are filled with air that is an infinitely resistant medium. Results showed that even small structures cause perceptible changes in resistivity that can be detected by the electrical resistivity method. Results also showed that specific software is required to predict real crack depth.
\end{abstract}

$\mathrm{O}$ N ARABLE LAND, soil can be compacted by traffic, hard setting, and crusting processes. Soil structure can be regenerated after compaction by tillage operations, biological processes, and climate processes. With new agricultural practices such as reduced tillage or no-tillage, soil structure mostly regenerates via natural processes. Thus, better understanding of climate effects is needed, especially the ability for soil to recover porosity by crack formation due to swelling and shrinking. Voorhees (1983) pointed out the role played by natural processes, such as soil freezing and thawing, and wetting and drying, decrease penetration resistance in the tilled layer of a compacted soil by about $50 \%$, depending on

A. Samouëlian and I. Cousin, INRA, Unité de Science du Sol, Avenue de la Pomme de Pin, BP 20619, 45166 Olivet, Cedex, France; G. Richard, INRA, Unité d'Agronomie, Rue Fernand Christ, 02007 Laon Cedex, France; A. Tabbagh, UMR 7619 “Sisyphe”, Case 105, 4 place Jussieu, 75005 Paris, France; A. Bruand, ISTO, Université d'Orléans, Géosciences, BP 6759, 45067 Orléans Cedex 2, France. Received 1 July 2002. *Corresponding author (samouelian@orleans.inra.fr).

Published in Soil Sci. Soc. Am. J. 67:1319-1326 (2003).

(C) Soil Science Society of America

677 S. Segoe Rd., Madison, WI 53711 USA soil water content. Mackie-Dawson et al. (1989) studied the evolution of the cracking system in the first $10 \mathrm{~cm}$ of soil by using vertical image analysis. They observed significant soil structural changes during an annual cycle of drying and wetting. Up to now, crack networks have been described traditionally, either by measuring manually in the field the crack geometry that forms at the soil surface (Blackwell et al., 1985; Lima and Grismer, 1992; Ringrose-Voase and Sanidad, 1996; Tuong et al., 1996), or automatically by using two-dimensional image analysis (Bullock and Murphy, 1980; Hallaire, 1984; McGarry et al., 2000; Scott et al., 1986; Stadler et al., 2000; Stengel, 1988; Velde et al., 1996). Image analysis was widely used to calculate morphological parameters of cracks. VandenBygaart et al. (1999) performed microscopic observations and showed a development of soil structure with time in an 11-yr chronosequence of no-tillage. They noticed that the number of horizontally oriented elongated macropores in the top 5 to $15 \mathrm{~cm}$ increased because of the absence of tillage and of the combination of annual freeze-thaw processes. McGarry et al. (2000) assessed soil structure from traditional and zero-till treatments in a Vertisol. They recorded a greater volume of large pores (1.5- to 3-mm equivalent diameter in size) after $8 \mathrm{yr}$ of zero-till and a greater volume of pores of smaller size (0.74- to $1.0-\mathrm{mm}$ equivalent diameter) after $8 \mathrm{yr}$ of traditional tillage.

Models that are based on these experimental observations and that describe crack growth are already available. Horgan and Young (2000) developed a two-dimensional empirical model based on random processes whose parameters are not directly related to the properties of a real soil. Perrier et al. (1999) used fractals to describe the cracking patterns that appeared in a homogeneous soil. Chertkov and Ravina (1998) developed a physically based probabilistic model of crack network geometry and observed a good agreement with one-dimensional experimental data. Hallaire (1988) used image analysis to describe a three-dimensional model with cubic geometry and isotropic shrinking.

However, because the tensile and shearing stresses 


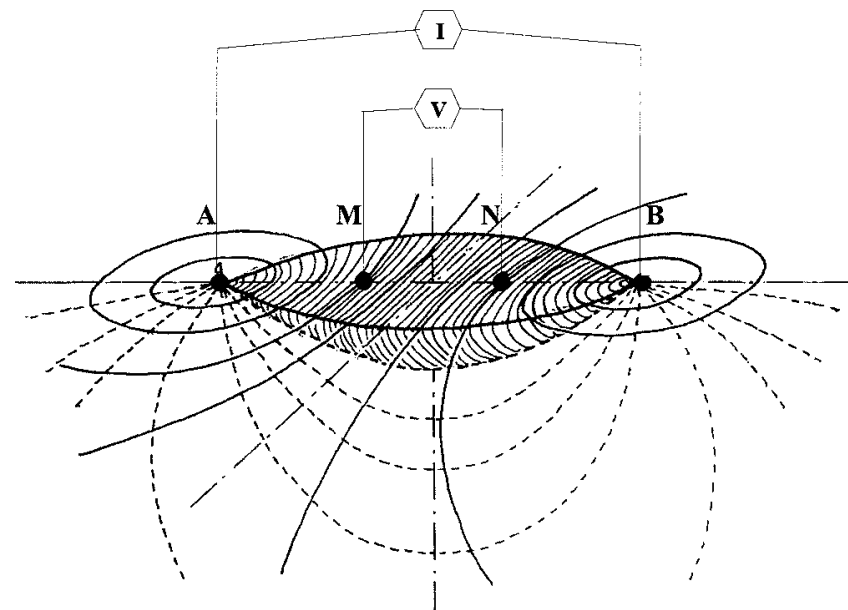

Fig. 1. Electrical distribution of current lines (dashed) and equipotential surface between two current electrodes $A$ and B; measure of electrical potential across the electrodes $M$ and $\mathrm{N}$ in a Wenner configuration.

vary in a soil with depth, we cannot realistically deduce soil behavior from the description of the surface alone. As a consequence, geometry of a crack network cannot be deduced from a two-dimensional description and geometrical analyses must provide three-dimensional information. In addition, most studies have used twodimensional vertical data obtained with destructive techniques, thus restricting the potential of these techniques for monitoring crack development. Therefore, the understanding of the dynamic processes of crack pattern growth requires the collection of three-dimensional data on a soil volume by using a non-destructive imaging technique. Electrical resistivity imaging is a geophysical investigation tool that has been used for many decades in hydrogeology, mining, oil and civil engineering, and archaeological prospecting. The technique is particularly useful in the study of complex geology (Griffiths and Barker, 1993), and has also been used for shallow subsurface investigation and environmental works (Hesse et al., 1986) as well as archaeological (Delapierre, 1998) and pedological surveys (Bourennane et al., 1998; Lamotte et al., 1994; Tabbagh et al., 2000). Electrical resistivity varies considerably according to the electrical conductivity of materials and their proportions in a soil volume. Dannowski and Yaramanci (1999), Goyal et al., (1996), Hagrey and Michaelsen (1999), Michot et al., (2000), and Zhou et al., (2001) related electrical resistivity to soil water content in their experiments. Acworth (1999) used this method to identify zones of high salt content in a clay layer. In these studies the electrical anomalies corresponded to large objects (i.e., larger than a decimetric size). Our objective is to adapt this method to identify small heterogeneities (i.e., objects of millimetric size) related to soil structure and especially to cracks developing during drying and wetting cycles. Since a crack in a drying context is air-filled, this structure should be easily detectable because of the infinite electrical resistivity of air. Consequently, we examined the ability of electrical resistivity surveys to distinguish small resistivity anomalies, with specially designed electrodes. This paper describes the first experi- ment to test the feasibility of electrical resistivity monitoring at this scale.

\section{Principle of Electrical Measurement Profile}

The general principle behind geophysical exploration is to collect data external to the medium under investigation but that are functions of the internal properties of this medium (Scollar et al., 1990). Andrews et al. (1995) defined electrical imaging as a picture of the electrical properties of the subsurface by passing an electrical current along many different paths and measuring the associated voltage. In the resistivity method, artificially generated electric currents are injected into the ground and the resulting differences of potential are measured at the surface. In practice, current $I(\mathrm{~A})$ is injected into the ground through two electrodes $\mathrm{A}$ and $\mathrm{B}$, and an electrical potential $\Delta V(\mathrm{~V})$ is measured across a second pair of electrodes $M$ and $\mathrm{N}$ (Fig. 1). In a homogenous terrain, the current is distributed in the ground between Points A and B with a regular geometric shape. In this distribution, the lines of current linking $\mathrm{A}$ and $\mathrm{B}$ and the equipotential surfaces which are close to hemispherical shape near A and B, cross each other. Current density is not equal at all points, and the main part of intensity $I$ emitted between $\mathrm{A}$ and $\mathrm{B}$ is concentrated in the hachured volume in the neighborhood of the AB segment (Fig. 1). This zone is related to the "higher sensitivity region" of the quadripole. This volume becomes larger as the distance AB increases. Soil apparent resistivity $(\rho)$ is calculated for a quadripole electrode (Fig. 1) as following:

$$
\begin{aligned}
\rho & =\frac{\Delta V}{I}\left(\frac{2 \pi}{(1 / \mathrm{MA}-1 / \mathrm{MB}+1 / \mathrm{NB}-1 / \mathrm{NA})}\right) \\
& =K \frac{\Delta V}{I}
\end{aligned}
$$

where $\rho$ is in $(\Omega \mathrm{m}), \mathrm{MA}, \mathrm{MB}, \mathrm{NB}, \mathrm{NA}$ are the interelectrode spacing $(\mathrm{m}), I$ the injected current, and $\Delta V$ the measured electrical potential (Scollar et al., 1990). This equation enables the determination of soil resistivity from four electrodes placed randomly on the surface. Constant $K$ is the geometric coefficient of the quadripole. In the case of the Wenner array, the electrodes are arranged in line and the current and potential electrodes are kept at an equal spacing $a(\mathrm{~m})$. Then, the geometric factor $K$ becomes $\mathrm{K}=2 \pi a$. The depth of investigation is a function of the distance between the nearest potential and current electrodes. The separation between the electrodes mainly determines the volume of soil detected by the instrument. The greater is the electrode spacing, the deeper is the investigation. The resistivity value is conventionally attributed to the geometric center point of the experimental array.

When the soil is not electrically homogeneous, the current lines and equipotential surfaces are distorted. Their patterns are no longer as described in Fig. 1. In this case, the resistivity measurement, obtained from $\Delta V$ and $I$, is called the apparent resistivity $\rho_{a}$. The latter is calculated with Eq. [1], and it provides qualitative 
information on the soil considered as a homogeneous equivalent medium.

\section{MATERIALS AND METHODS}

\section{The Soil Studied}

The experiments were conducted in the laboratory on an air-dried soil sample $\left(2.4\right.$ by 1.7 by $\left.1.6 \mathrm{dm}^{3}\right)$ with an initial massive structure resulting from severe compaction by wheel traffic. The sample was collected in the tilled horizon of a silt loam (Typic Hapludalf) located on an experimental site in the National Institute for Agronomic Research Center at Mons en Chaussée (Somme, France) (Richard et al., 2001). An apparent vertical two-dimensional electrical resistivity pseudosection was first measured along a $21-\mathrm{cm}$ line from the top surface of the soil block (Stage A with no crack). Then cracks were made manually. In terms of electrical prospecting, the crack is air-filled and corresponds to a resistant structure. A crack of 2-mm width and varying depths $(1,2,3$, and $4 \mathrm{~cm}$ deep) was created artificially with a saw to obtain four cracking stages (B, C, D, and E) in the soil sample. The physical model used for soil fractures was intentionally simplistic because this experimentation consists in a feasibility test of electrical measurements. All the measurements were conducted on the soil sample the same day under controlled conditions (room temperature $22^{\circ} \mathrm{C}$ ). The experiment lasted $4 \mathrm{~h}$ and the volumetric water content was $0.09 \mathrm{~cm}^{3} \mathrm{~cm}^{-3}$ and remained stable throughout the experiment. The variation of resistivity was then related to the variation of the structure alone.

\section{Microelectrodes}

Our experiment focused on the top $10 \mathrm{~cm}$ of the soil, thus the electrical array required centimetric interelectrode spacing. Because of the unusually close electrode spacing associated with an air-dried soil surface, a specific electrode device was designed to improve the electrical contact between the dried soil surface. Indeed, classical electrodes such as metal needles do not permit a correct electrical contact with a soil when it dries. We then designed a new electrode that enables a wet contact between the electrode and the soil surface. Figure 2 shows this specific electrode, manufactured from a smallsaturated cone-shaped ceramic cup (2-mm external diameter) linked to a $\mathrm{Cu} / \mathrm{CuSO}_{4}$ complex. The copper wire had a section of $0.6 \mathrm{~mm}$, and the concentration of the $\mathrm{CuSO}_{4}$ solution was $0.05 \mathrm{~mol} \mathrm{~L}^{-1}$. The ceramic cup was joined to a transparent plastic rigid tube (3-mm external diameter and 2-mm internal diameter). The saturated ceramic cup placed on the soil surface permitted a wet contact. Blotting paper protected the soil surface during the installation of the device, so that all the electrodes reached the soil surface at the same time when the paper was removed. The measurements were performed as soon as the electrodes were placed in contact with the soil, to avoid variation of the electrical response of the soil because of infiltration of some $\mathrm{CuSO}_{4}$ solution in the soil porosity.

\section{Two-Dimensional Vertical Pseudo-Section}

To detect the crack, its lateral position and its depth, a 21-cm line of 15 electrodes each separated by a constant distance $a$ $(1.5 \mathrm{~cm})$ was installed at the soil block surface. The crack was located between Electrodes 8 and 9. A Wenner array was used to monitor the electrical potential (Fig. 3). The first four electrodes 1, 2, 3, and 4 were connected as A, M, N, and B (Station 1). A second measurement was performed by disconnecting the first four electrodes and moving the array along the 21-cm measurement line by a single electrode spacing $a$

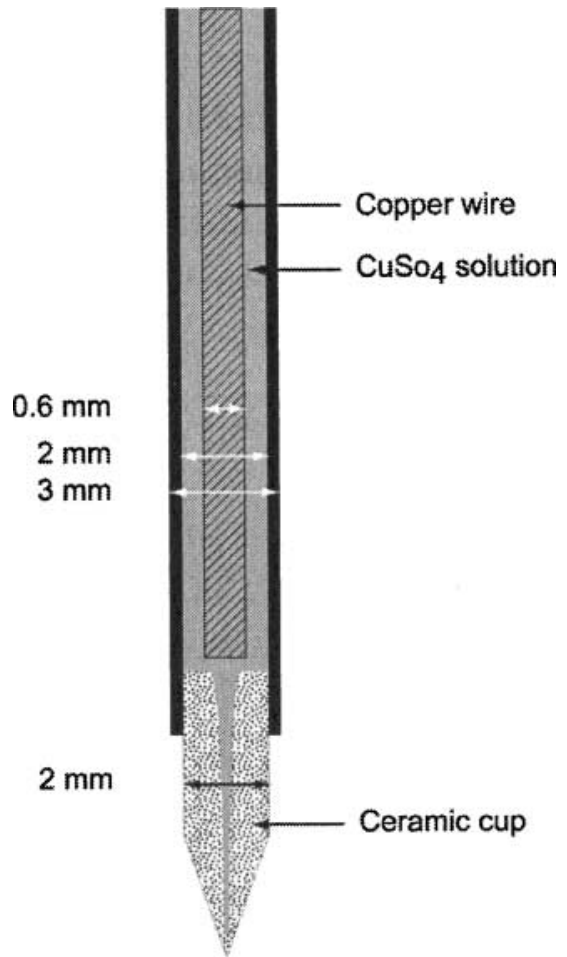

Fig. 2. Electrode device.

and connecting the array to Electrodes 2, 3, 4, and 5. The process was repeated until reaching the end of the line. Then a second profile was recorded by connecting the electrodes in a way that $\mathrm{A}, \mathrm{M}, \mathrm{N}$, and $\mathrm{B}$ occupied electrode positions 1 , 3,5 , and 7 (Station 2). The array was then moved along the line by a $2 a$ spacing. The process was repeated by increasing the electrode spacing each time by multiple $\mathrm{N}$ of the initial electrode spacing, which resulted in four depth measurements. For each measurement, the selection of electrodes connected to the resistivity meter (Syscal-R1 Plus, Iris Instrument, Orléans, France) was controlled by an automatic computer-controlled switch array (Multinode). Intensity $I$ injected through the $\mathrm{A}$ and $\mathrm{B}$ electrodes varied from 2 to $3.5 \mathrm{~mA}$ while the electrical potential varied from 251 to $3231 \mathrm{mV}$. With this configuration, 12, 9, 6, and 3 measurements were performed as the spacing multiple $\mathrm{N}$ increased from 1 to 4 . The measured values were plotted on a measurement map at the intersections of lines sloping at $45^{\circ}$ from the centers of the quadripole. The values were thus plotted along the depth, which reflects the

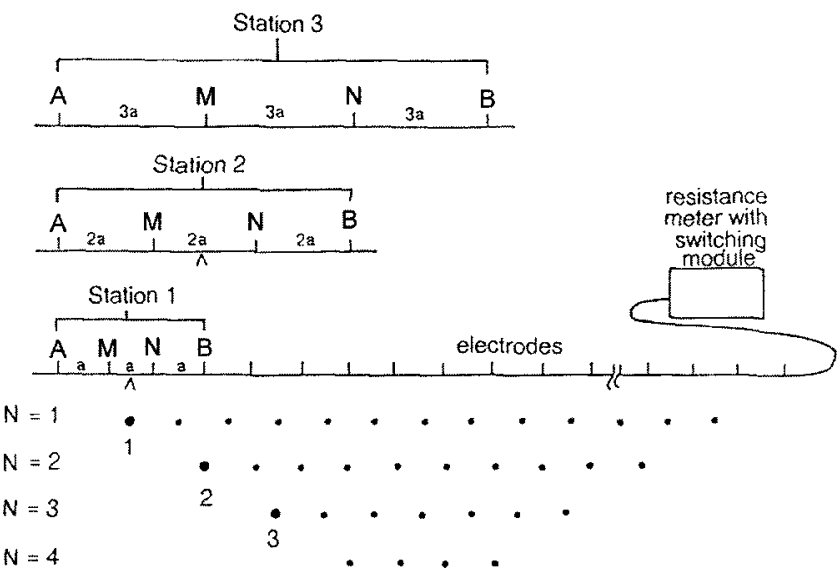

Fig. 3. The measurement sequence for building up a pseudo-section. 


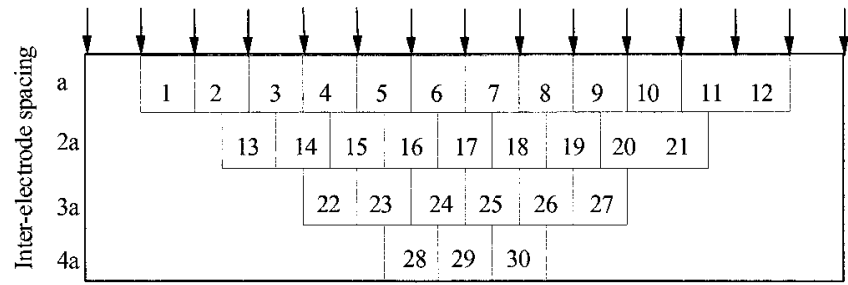

Fig. 4. Measurement map of an apparent electrical resistivity pseudosection in a Wenner configuration of 15 electrodes.

increasing depth of current penetration as the interelectrode spacing $a$ increased. It should be noted that the units on the vertical axis of the measurement map (Fig. 4) are multiple values of the interelectrode spacing $a$, from $a$ to $4 a$. Thus, there were 30 separate apparent resistivity measurements. As the interelectrode spacing $a$ increased, the measurements sampled increasingly greater depths and increasingly greater volumes of soil. In other words, the total soil volume affected by the current injection rose as the interelectrode spacing $a$ increased. The measurement was plotted beneath the center of the four electrodes.

\section{Resistivity Inversion}

The heterogeneities that are present in a soil disturb the theoretical current distribution. The electrical measurement involves a given volume of soil within which the presence of heterogeneity affects the overall measured value. Thus the pseudo-section of apparent resistivity gives a qualitative spatial distribution of electrical resistivity in vertical cross-section. A quantitative approach therefore requires a mathematical inversion of the apparent electrical resistivity into interpreted resistivity. Numerical inversion of the experimental apparent resistivity was performed using Res2Dinv software (Loke and Barker, 1996). This software is widely used in electrical surveys (Acworth, 1999; Delapierre, 1998; Michot et al., 2000). This method is based on the smoothness-constrained least squares method applied to apparent electrical resistivity. The volume of influence described by the apparent resistivity is translated into the depth of investigation related to the interpreted resistivity. The two-dimensional model divides the subsurface into a number of rectangular blocks as shown in Fig. 5. Regarding the Wenner array, the thickness of the first layer of blocks is based on experimental results (Edwards, 1977). The depth corresponds to the "median depth of investigation" $a / 2$. The thickness of each subsequent deeper layer is increased normally by $10 \%$. Figure 6 shows the successive stages of the inversion method. Initially, an interpreted resistivity pseudosection is calculated from the measured apparent resistivity

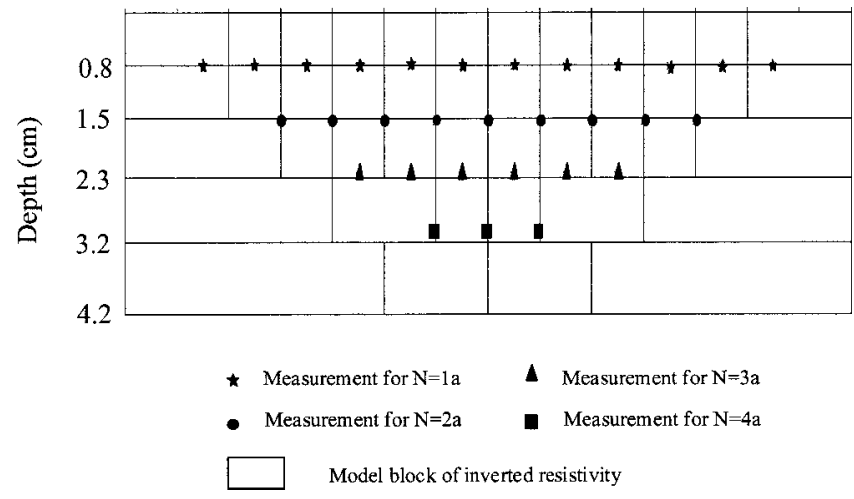

Fig. 5. Arrangement of model blocks and apparent resistivity data points in a Wenner array. pseudo-section. The second stage then consists in resolving the direct problem (i.e., in calculating the apparent resistivity pseudo-section from the inverted resistivity pseudo-section previously obtained in the first stage). In the third stage, the algorithm calculates the difference between the measured and calculated apparent pseudo-sections. An iterative process is performed until the difference became small enough. The optimization method reduces the differences between the calculated and measured resistivity values by adjusting the resistivity of the model blocks. The measurement of this difference is given by the root mean square error (RMSE) as following:

$$
\mathrm{RMSE}=\sqrt{\frac{1}{n} \sum_{i=1}^{n}\left(\rho_{\mathrm{c}}-\rho_{\mathrm{m}}\right)^{2}}
$$

where $\rho_{\mathrm{c}}, \rho_{\mathrm{m}}$, and $n$ are respectively the apparent resistivity simulated by the Res2Dinv software, the apparent resistivity measured during the experiment and the number of data points.

\section{RESULTS}

\section{Apparent Resistivity Interpretation}

Figure 7 shows the apparent electrical resistivity pseudo-sections for the cracking Stages A, B, C, D, and E. The set of five profiles describes the artificial growth of the crack located between Electrodes 8 and 9. Map representations are only based on experimental values. No interpolated values were added. Consequently, each mesh represented a data point value corresponding to a Wenner array. Stage A represented the initial soil massive structure, without any crack. The corresponding electrical pseudo-section exhibited a homogeneous apparent resistivity of $47 \Omega \mathrm{m}$. The further Stages B, C, $\mathrm{D}$, and $\mathrm{E}$, presented electrical differentiations directly above the crack between Electrodes 8 and 9. The deeper was the crack in this configuration, the higher was the apparent resistivity. The resistivity range varied from 52 to $77 \Omega \mathrm{m}$. Another demonstration of the resistivity modification can be represented by positive electrical anomaly (Fig. 8). The resistivity anomaly was calculated as following:

$$
\Delta \rho_{\mathrm{a}}=\frac{\left(\rho_{\mathrm{a}, \mathrm{X}}-\rho_{\mathrm{a}, \mathrm{A}}\right)}{\rho_{\mathrm{a}, \mathrm{A}}}
$$

where $\rho_{\mathrm{a}, \mathrm{A}}$ and $\rho_{\mathrm{a}, \mathrm{X}}$ were respectively the apparent resistivity of the initial Stage A and the apparent resistivity of the different cracking growing stages $(\mathrm{X}=\mathrm{B}, \mathrm{C}, \mathrm{D}$, or E). All four individual pseudo-sections showed a similar anomaly distribution. Directly above the crack, the positive anomaly varied from 38 to $104 \%$ respectively for Stages B and E. Our results also showed that not only the amplitude of the apparent resistivity anomalies increased as the crack grew, so did also its downward extension. The classical reversed V-shape on the map corresponded to a vertical plane electrical discontinuity. Both the apparent resistivity and the anomalies (Fig. 7 and 8) remained constant outside the area of crack influence. This is consistent with no variation of the water content in the soil block throughout experimentation and confirms that the electrical resistivity measurement was affected by variation of the soil struc- 


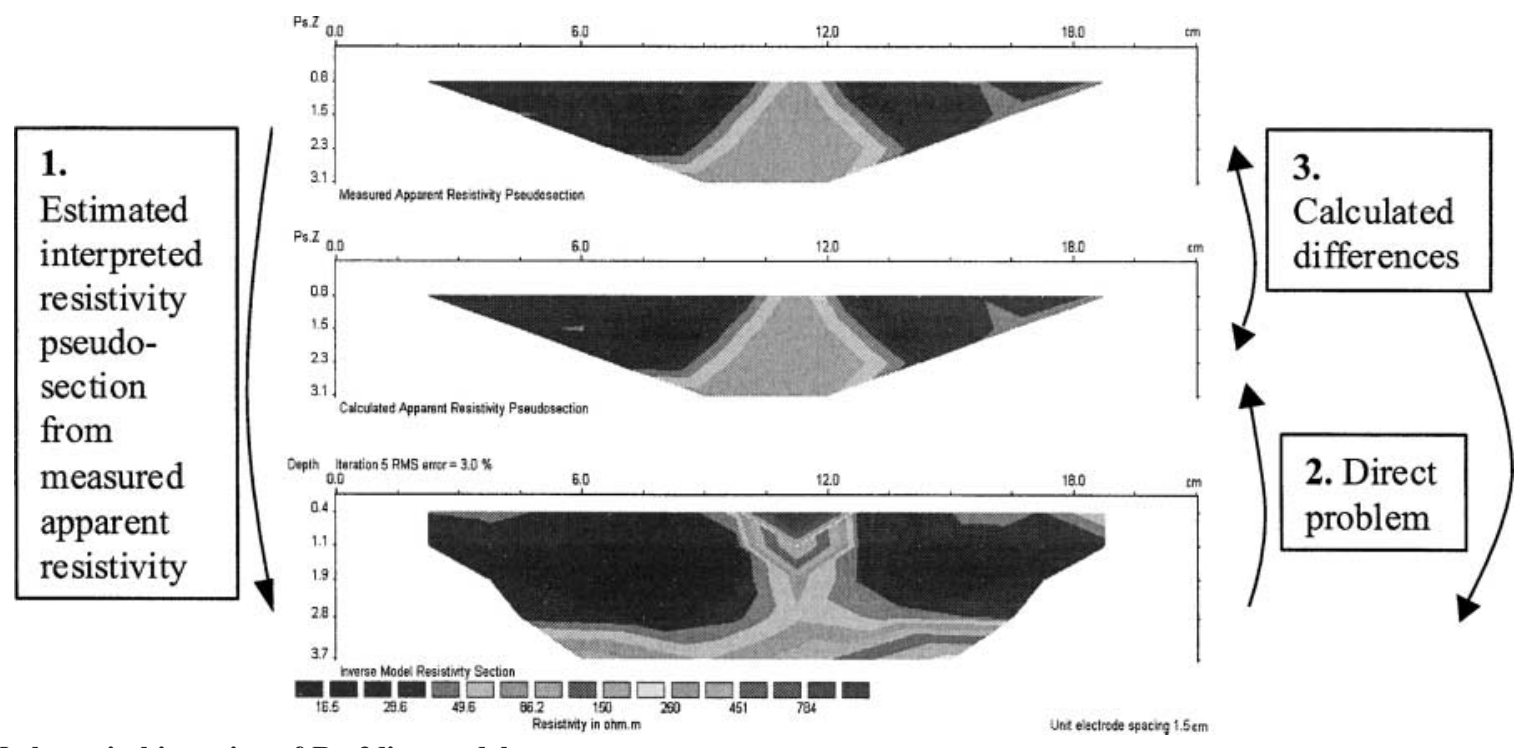

Fig. 6. Mathematical inversion of Res2dinv model.

ture alone in our experiment. As expected, the positive anomaly corresponded to the electrical crack signature, as a resistant object that could be detected by resistivity measurement.

\section{Quantitative Resistivity Interpretation: Resistivity Inversion}

The measured apparent resistivity pseudo-sections were analyzed by using the Res2Dinv software to calculate interpreted resistivity pseudo-sections. The latter are shown in Fig. 9 for Stages A, B, C, D, and E. In our case, five iterations for the inversion were usually enough to derive a model distribution producing a result with an RMSE lower than 5\%. Initial soil block resistivity at Stage A was relatively homogenous being equal to $37 \Omega \mathrm{m}$. For Stages B, C, D, and E, the calculated interpreted resistivity clearly showed zones of higher electrical resistivity, from 168 to $2185 \Omega$ m between the Electrodes 8 and 9 . This high resistivity was directly correlated with the growing crack 1 to $4 \mathrm{~cm}$ deep. The highest heterogeneity amplitude was located at $0.8-\mathrm{cm}$ depth. The magnitude of the interpreted variation decreased as the electrode spacing increased.

Figure 10 illustrates the vertical sensitivity of interpreted resistivity during cracking stages. The variation of crack depth from 1 to $4 \mathrm{~cm}$ influenced electrical resistivity distribution. The interpreted resistivity, in the first $0.8-\mathrm{cm}$ depth, increased from 168 to $2185 \Omega \mathrm{m}$ as the crack grew from 1 to $4 \mathrm{~cm}$. The electrical resistivity in the second horizontal layer (0.8- to $1.5-\mathrm{cm}$ depth) rose by $10 \%$ between Stages B $(32 \Omega \mathrm{m})$ and E. Beyond the 1.5-cm depth layer, resistivity remained stable even for a 4-cm crack depth. The first horizontal layer was the most sensitive to structural changes.

Figure 11 illustrates the horizontal sensitivity of interpreted resistivity during cracking stages for the first depth layer $(0-0.8 \mathrm{~cm})$. Stage A, represented the initial soil structure without any crack or any significant electrical variation. Directly above Electrodes 8 and 9, the electrical signature of the crack increased as the crack grew, as shown in Fig. 10. The lateral sensibility is related to the following point measurement, $1.5-\mathrm{cm}$ apart. Progression was the same for all cracking stages, B, C, D, and $\mathrm{E}$, characterized by decreased electrical resistivity in the crack site. The decrease was highest for Stage E, corresponding to a fall of $98 \%$ at the $1.5-\mathrm{cm}$ distance. The resistivity contrast between the crack and the soil was abrupt. The lateral influence of the $2-\mathrm{mm}$ width vertical crack was negligible.

\section{DISCUSSION}

This experimental survey focuses on electrical resistivity response from subsurface varying structures. Analyzing the vertical interpreted pseudo-sections revealed the presence of high resistivity contrasts in a vertical zone located at the position of the crack, between Electrodes 8 and 9. This demonstrated the effect of soil structure on the electrical resistivity measurement. The new ceramic cup electrodes enabled efficient electrical monitoring in dry soil. Although the shortest interelectrode spacing was $1.5 \mathrm{~cm}$ the principle of point source electrical measurement was respected owing to the wet contact at the soil surface through the small (millimeter) electrodes.

Experiment conditions warranted stable water content during measurements. Göbel et al. (1993), Hagrey and Michaelsen (1999), and Michot et al. (2000) studied the variation of electrical resistivity in the subsurface in water infiltration experiments. The range of interpreted resistivity measurement varied from low resistivity 10 $\Omega \mathrm{m}$, corresponding to wet conditions, to $200 \Omega \mathrm{m}$ for dry conditions. In our experiment, high and abrupt electrical resistivity measurements ranging from 48 to $2185 \Omega \mathrm{m}$ were recorded and attributed to the artificial crack. The crack was filled with air and represented a resistant structure in terms of electrical prospecting. The interpreted resistivity pseudo-sections permitted detection of crack location between Electrodes 8 and 9, on the one hand, and crack vertical orientation on the other 

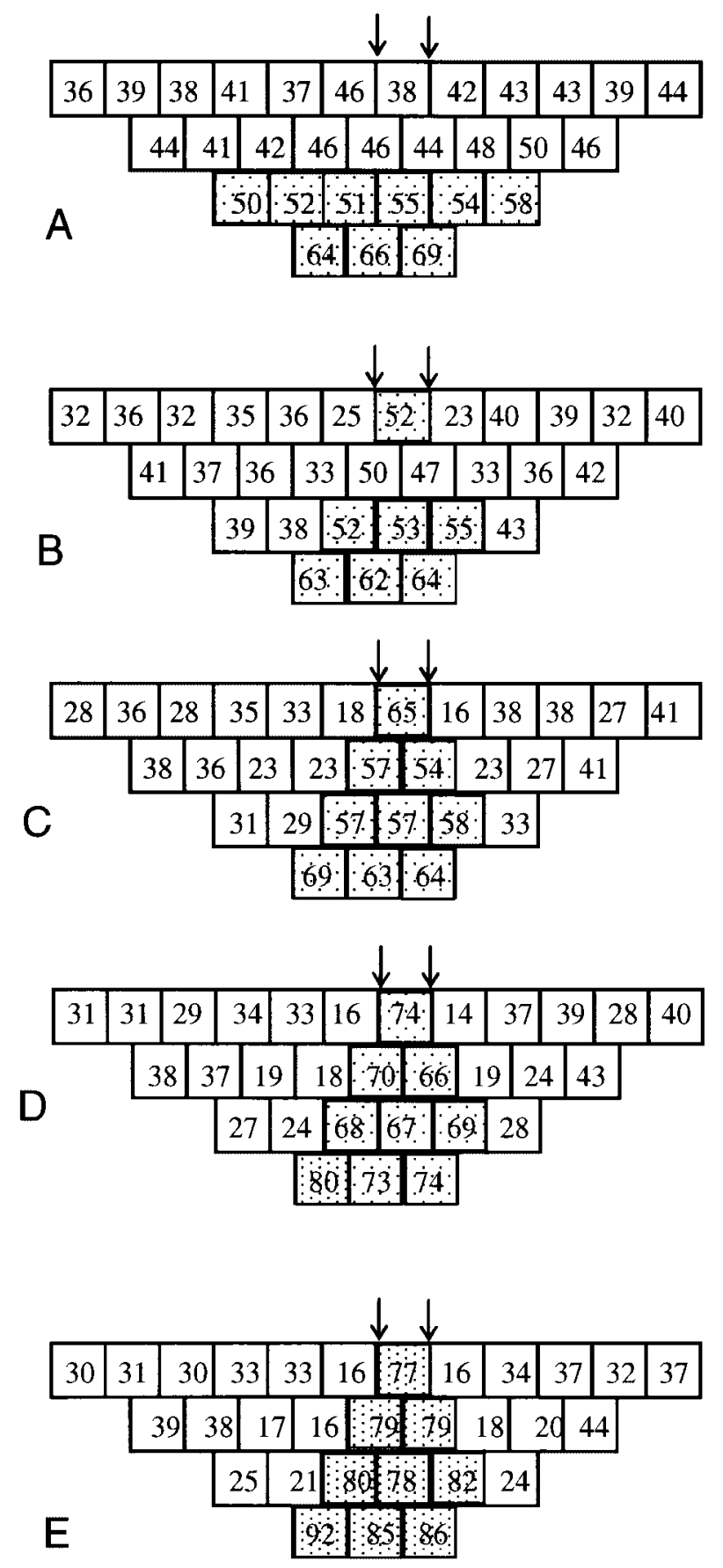

\section{$\because \because]$ \\ $507515020030050015002000 \Omega m$}

Fig. 7. Apparent resistivity pseudo-section for the five stages, crack localization between the Electrodes 8 and 9.

hand. We did not expect variation of the top centimeters of the soil between the following cracking stages, though we did expect agreement between crack electrical signa-
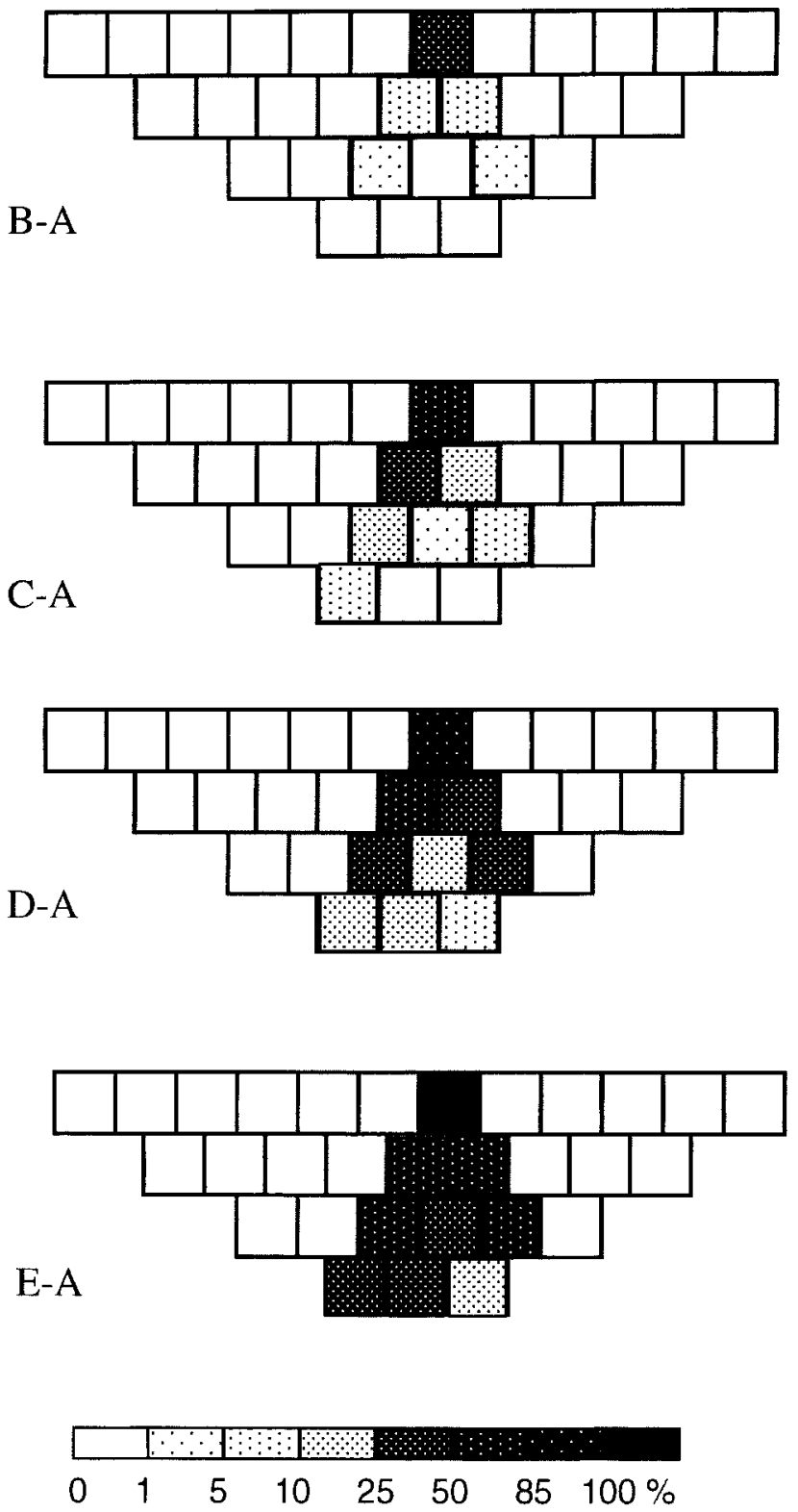

Fig. 8. Resistivity anomalies during the different stages along the profile.

ture and crack depth. The highest interpreted electrical resistivity was recorded in the top $1.5-\mathrm{cm}$ depth, whereas the crack developed down to $4 \mathrm{~cm}$. Similarly, Griffiths and Barker (1993) observed that detection and resolution both decreased with depth, setting limits on the degree of geological complexity. The actual interpreted data permitted to detect the presence of the crack, but did not allow predicting its depth. Crack depth variation was represented with a significant variation of the interpreted resistivity at the subsurface. These results led us to reconsider the inversion model: the Res2Dinv software cannot totally succeed in detecting abrupt structure geometry variations and strong electrical resistivity gradients because the numerical resolution of the mathematical algorithm is based on a regular mesh and a smoothness condition. However, this study suggests that even small structures, such as millimetric cracks, cause a significant change in resistivity distribution. 

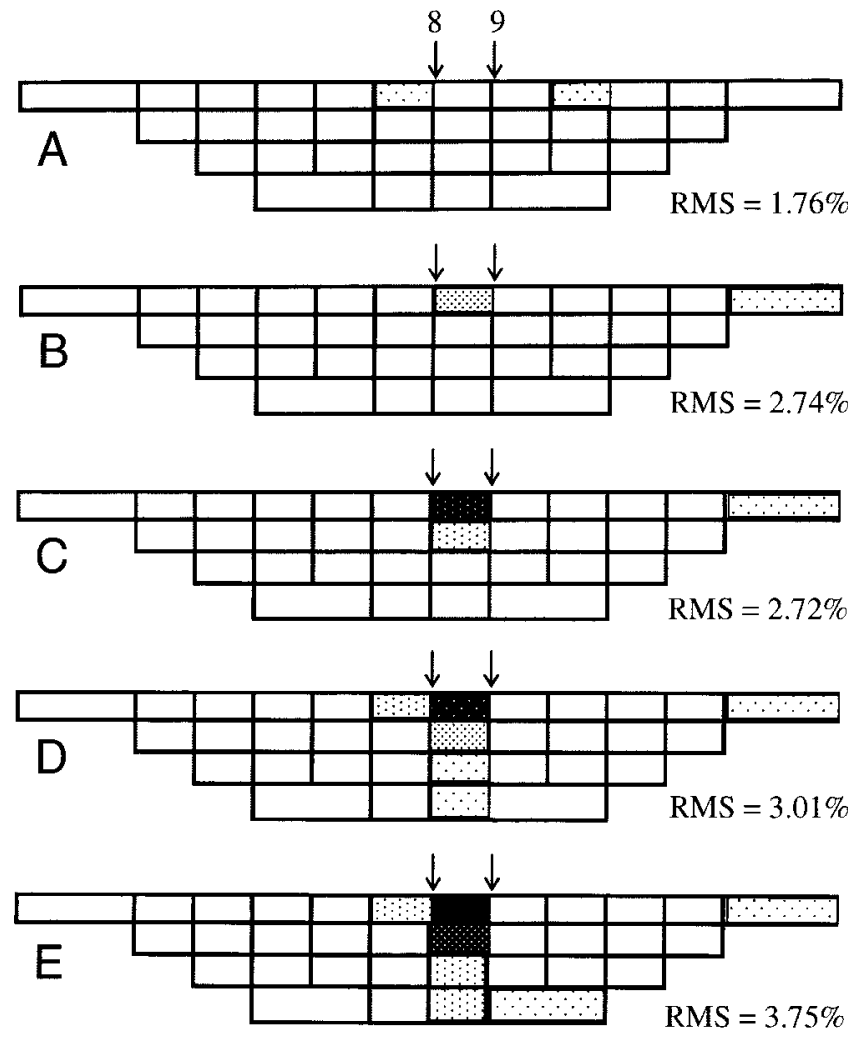

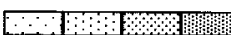

$5075 \quad 15020030050015002000 \Omega m$

Fig. 9. Interpreted resistivity pseudo-section for the Stages A, B, C, D, and E.

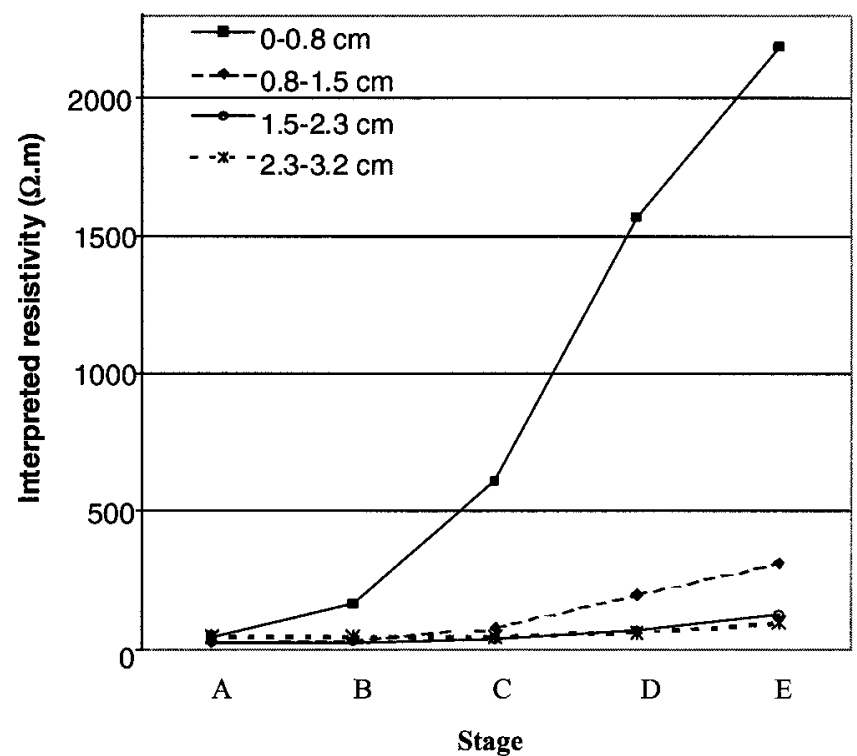

Fig. 10. Interpreted resistivity variation between the Electrodes 8 and 9 during the following cracking stages and for different depth investigation.

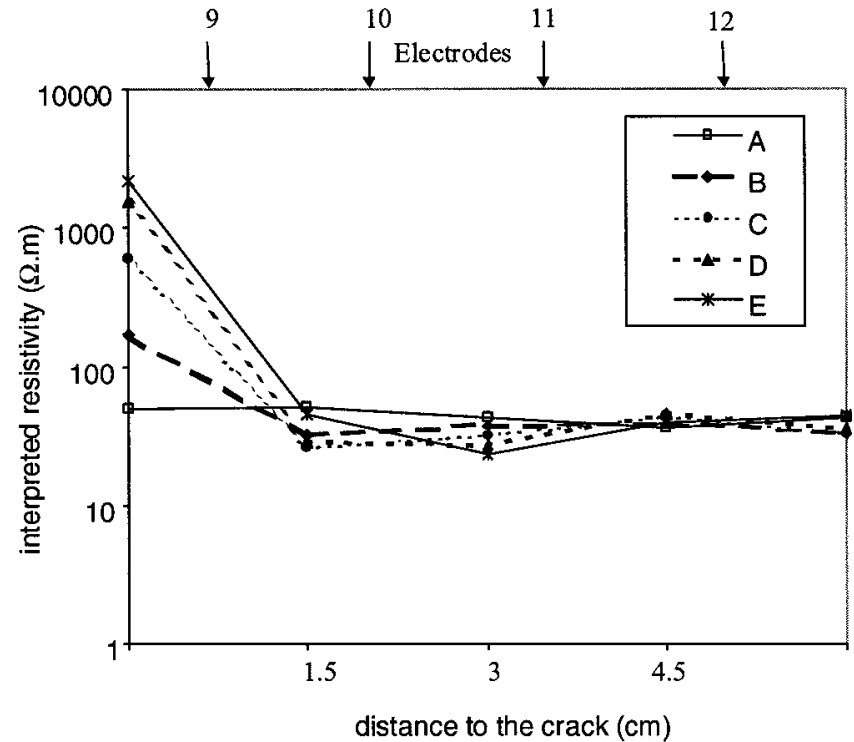

Fig. 11. Lateral variation of interpreted resistivity as a function of crack localization, for the first depth layer 0 to $0.8 \mathrm{~cm}$.

\section{CONCLUSION}

The electrical resistivity image method is a relatively rapid method that can be used to investigate soil structure. The method produces a two-dimensional vertical section of interpreted electrical resistivity from the measurement of apparent resistivity. Our results demonstrate the effectiveness of electrical resistivity prospecting in characterizing soil cracks that form during shrinking and swelling phenomena at the centimetric scale. The $\mathrm{Cu} / \mathrm{CuSO}_{4}$ electrodes combined with a saturated ceramic cup permitted a correct electrical contact of the electrode with the soil surface. Regarding subsurface formation, the electrical images obtained from these electrodes enable detection of structures at the millimeter scale. This experiment is a first step in crack detection by using the electrical resistivity method.

Compared with other crack determination studies, the electrical resistivity method permits non-invasive measurements. These first results based on artificial cracks with two-dimensional imaging exploration are encouraging, but they confirm the need for future work on the inversion of the apparent resistivity data. Future work will consist in adapting this electrical monitoring to a soil block under desiccation condition to monitor a real crack network as it grows. Nevertheless, more detailed analysis of crack network requires appreciation of the entire volume of soil and not only of a twodimensional section. Thus we will also develop a threedimensional electrical resistivity set-up.

\section{ACKNOWLEDGMENTS}

The authors gratefully thank Keith Hodson for improving our English.

\section{REFERENCES}

Acworth, R.I. 1999. Investigation of dryland salinity using the electrical image method. Austr. J. Soil Res. 37:623-636.

Andrews, R.J., R. Barker, and L. Meng Heng. 1995. The application 
of electrical tomography in the study of the unsatured zone in chalk at three sites in Cambridgeshire, United Kingdom. Hydrogeology J. 3:17-31.

Blackwell, P.S., M.A. Ward, R.N. Lefevre, and D.J. Cowan. 1985. Compaction of a swelling clay soil by agricultural traffic; effects upon conditions for growth of winter cereals and evidence for some recovery of structure. J. Soil Sci. 36:633-650.

Bourennane, H., D. King, R. Le Parco, M. Isambert, and A. Tabbagh. 1998. Three-dimensional analysis of soils and surface materials by electrical resistivity survey. Eur. J. Env. Eng. Geoph. 3:5-23.

Bullock, P., and C.P. Murphy. 1980. Toward the quantification of soil structure. J. Microsc. 120:317-328.

Chertkov, V.Y., and I. Ravina. 1998. Modeling the crack network of swelling clay soils. Soil Sci. Soc. Am. J. 62:1162-1171.

Dannowski, G., and U. Yaramanci. 1999. Estimation of water content and porosity using radar and geoelectrical measurements. Eur. J. Env. Eng. Geoph. 4:71-85.

Delapierre, A. 1998. Représentation en 3D d'une partie des vestiges d'une villa gallo-romaine à l'aide des méthodes életriques (Site gallo-romain d'Orbe-Boscéaz, Vaud, Suisse). (In French.) Mémoire de Master Institut de géophysique de Lausanne.

Edwards, L.S. 1977. A modified pseudosection for resistivity and IP. Geophysics 42:1020-1036.

Göbel, B., J. Michaelsen, E. Danchwardt, S.A. Hagrey, C. Meyer, G. Petzold, C. Stolte, and R. Thierbach. 1993. Geophysikalische Methoden zur Erfassung von Wasserverteilungen and Wassertransportvorgängen in Böden. (In German.) Mitteilgn. Deutsche. Bodenkundl. Gesellsch. 72:111-114.

Goyal, V.C., P.K. Gupta, P.K. Seth, and V.N. Singh. 1996. Estimation of temporal changes in soil moisture using resistivity method. Hydr. Proc. 10:1147-1154.

Griffiths, D.H., and R.D. Barker. 1993. Two-dimensional resistivity imaging and modelling in areas of complex geology. J. Appl. Geophysics 29:211-226.

Hagrey, S.A.A., and J. Michaelsen. 1999. Resistivity and percolation study of preferential flow in vadose zone at Bokhorst, Germany. Geophysics 64:746-753.

Hallaire, V. 1984. Evolution des reseaux de fissure lors du retrait d'un sol argileux. (In French.) (Cracks patterns evolution during shrinking in clayey soil) p. 323-327. In Fonctionnement hydrique et comportement des sols AFES, Dijon.

Hallaire, V. 1988. La fissuration d'un sol argileux au cours du dessèchement. II Modélisation morphologique (In French). Agronomie 8: 273-280.

Hesse, A., A. Jolivet, and A. Tabbagh. 1986. New prospects in shallow depth electrical surveying for archeological and pedological applications. Geophysics 51:585-594.

Horgan, G.W., and I.M. Young. 2000. An empirical stochastic model for the geometry of two-dimensional crack growth in soil (with discussion). Geoderma 96:263-276.

Lamotte, M., A. Bruand, M. Dabas, P. Donfack, G. Gabalda, A. Hesse, F.X. Humbel, and H. Robain. 1994. Distribution d'un horizon à forte cohésion au sein d'une couverture de sol aride du NordCameroun: apport d'une prospection électrique (In French). C.R. Acad. Sci. 318:961-968.
Lima, L.A., and M.E. Grismer. 1992. Soil Crack Morphology and Soil Salinity. Soil Sci. 153:149-153.

Loke, M.H., and R.D. Barker. 1996. Rapid least-squares inversion of apparent resistivity pseudosections using a quasi-Newton method. Geophys. Prosp. 44:131-152.

Mackie-Dawson, L.A., C.E. Mullins, E.A. Fitzpatrick, and M.N. Court. 1989. Seasonal changes in the structure of clay soils in relation to soil management and crop type. I Effects of crop rotation at Cruden Bay. NE Scotland. J. Soil Sci. 40:269-281.

McGarry, D., B.J. Bridge, and B.J. Radford. 2000. Contrasting soil physical properties after zero and traditional tillage of an alluvial soil in the semi-arid subtropics. Soil Tillage Res. 53:105-115.

Michot, D., A. Dorigny, and Y. Benderitter. 2000. Mise en évidence par résistivité électrique des écoulements préférentiels et de l'assèchement par le maïs d'un calcisol de Beauce irrigué. (In French) C.R. Acad. Sci. 332:29-36.

Perrier, E., N. Bird, and M. Rieu. 1999. Generalizing the fractal model of soil structure: the pore-solid fractal approach. Geoderma 88: 137-164.

Richard, G., J.F. Sillon, and O. Marloie. 2001. Comparaison of inverse and direct evaporation methods for estomating soil hydraulic properties under different tillage practices. Soil Sci. Soc. Am. J. 65: 215-224.

Ringrose-Voase, A.J., and W.B. Sanidad. 1996. A method for measuring the development of surface cracks in soils: application to crack development after lowland rice. Geoderma 71:245-261.

Scollar, I., A. Tabbagh, A. Hesse, and I. Herzog. 1990. Archaeological prospecting and remote sensing. Cambridge Univ. Press, New York.

Scott, G.J.T., R. Webster, and S. Nortcliff. 1986. An analysis of crack pattern in clay soil: its density and orientation. J. Soil Sci. 37: 653-668.

Stadler, D., M. Stähli, P. Aeby, and H. Flühler. 2000. Dye tracing and image analysis for quantifying water infiltration into frozen soils. Soil Sci. Soc. Am. J. 64:505-516.

Stengel, P. 1988. Cracks formation during swelling: Effect on soil structure regeneration after compaction. p. 147-152. In Proc. 11th Conference of ISTRO, Edinburgh (Scotland). ISTRO, Haren, the Netherlands.

Tabbagh, A., M. Dabas, A. Hesse, and C. Panissod. 2000. Soil resistivity: A non-invasive tool to map soil structure horizonation. Geoderma 97:393-404.

Tuong, T.P., R.J. Cabangon, and M.C.S. Wopereis. 1996. Quantifying flow processes during land soaking of cracked rice soils. Soil Sci. Soc. Am. J. 60:872-879.

VandenBygaart, A.J., R. Protz, and A.D. Tomlin. 1999. Changes in pore structure in a no-till chronosequence silt loam soils, southern Ontario. Can. J. Soil Sci. 79:149-160.

Velde, B., E. Moreau, and F. Terrible. 1996. Pore networks in an italian Vertisol: Quantitative characterization by two dimensional image analysis. Geoderma 72:271-285.

Voorhees, W.B. 1983. Relative effectiveness of tillage and natural forces in alleviating wheel-induced soil compaction. Soil Sci. Soc. Am. J. 47:129-133.

Zhou, Q.Y., J. Shimada, and A. Sato. 2001. Three-dimensional spatial and temporal monitoring of soil water content using electrical resistivity tomography. Water Resour. Res. 37:273-285. 